\title{
Semi-Active Suspension Control Considering Lateral Vehicle Dynamics Due to Road Input
}

\author{
Takama Suzuki and Masaki Takahashi \\ Additional information is available at the end of the chapter
}

http://dx.doi.org/10.5772/45789

\section{Introduction}

An automotive performance has improved from the demand of ride comfort and driving stability. Many research have proposed various control system design methods for active and semi-active suspension systems. To improve vehicle response by steering, a roll angle control [1], a distribution control of the suspension stiffness of front and rear [2], and pitch angle control [3][4] have been proposed. Furthermore, to improve vehicle response due to disturbance on the road, a tire vertical load control [4-6] caused by road disturbance was proposed. In recent year, it is reported that roll and lateral vehicle motions are affected by the road input. These motions are affected by not only road displacement but also the change of tire side force [8-11]. As shown in Figs. 1 and 2, the tire side force is caused by a toe change and a scuff due to the roll motion and tire side force. However, there are few research about a suspension control method which takes into consideration with a suspension characteristic that is change of tire side force caused by suspension stroke and tire side force.

In this research, we designed a suspension control system which reflects a suspension characteristic, the change of tire side force caused by suspension stroke and tire side force. A new semi-active suspension control method is proposed to reduce the vehicle vibration and vehicle lateral motion due to the road input.

To design such a system, the time delay of the road input from the front wheel to the rear wheel needed to be modeled. In the vehicle control, there are several control systems which take into consideration with this delay [12-16]. However, the purpose of these research is to find a way to reduce the vehicle vertical vibration. Oraby evaluated motion of the vehicle lateral direction [7]. However, the dynamics of the lateral direction do not be considered in the control system design. 


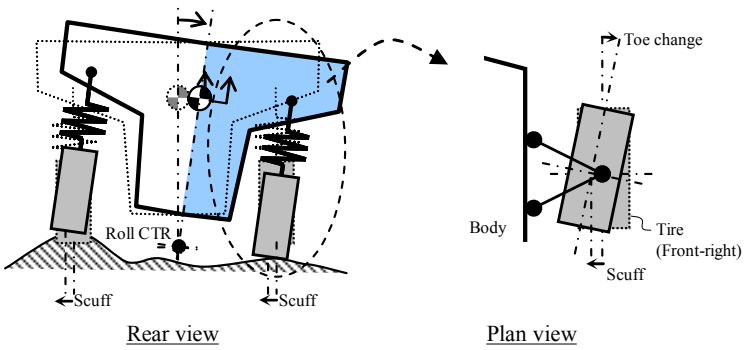

(a) Roll motion.

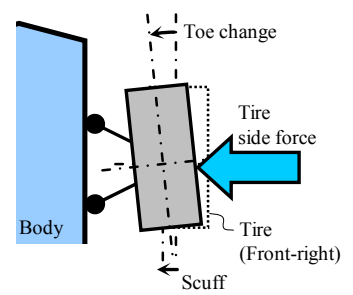

Plan view

(b) Tire side force

Figure 1. Toe change and scuff caused by roll motion and tire side force.

\begin{tabular}{l|ll||l|ll}
\hline Symbol & Value & & Symbol & Value & \\
\hline$M_{b}$ & 1900 & $\mathrm{~kg}$ & $K_{t}$ & $260 \times 10^{3}$ & $\mathrm{~N} / \mathrm{m}$ \\
$M_{t}$ & 50 & $\mathrm{~kg}$ & $l_{f}$ & 1.34 & $\mathrm{~m}$ \\
$I_{r}$ & 600 & $\mathrm{kgm}^{2}$ & $l_{r}$ & 1.46 & $\mathrm{~m}$ \\
$I_{p}$ & 3000 & $\mathrm{kgm}^{2}$ & $T_{f}$ & 1.50 & $\mathrm{~m}$ \\
$I_{y}$ & 3200 & $\mathrm{kgm}^{2}$ & $T_{r}$ & 1.50 & $\mathrm{~m}$ \\
$K_{f}$ & $33 \times 10^{3}$ & $\mathrm{~N} / \mathrm{m}$ & $h_{r}$ & 0.45 & $\mathrm{~m}$ \\
$K_{r}$ & $31 \times 10^{3}$ & $\mathrm{~N} / \mathrm{m}$ & $h_{p}$ & 0.53 & $\mathrm{~m}$ \\
$C_{f}$ & \multicolumn{2}{|l}{ Discuss in section 3.3 } & $h_{r f}$ & 0.62 & $\mathrm{~m}$ \\
$C_{r}$ & \multicolumn{2}{|l}{ Discuss in section 3.3 } & $h_{r r}$ & 0.11 & $\mathrm{~m}$ \\
\hline
\end{tabular}

Table 1. Specification of vehicle model

In order to design the controller, a vehicle model including the tire side force change caused by road disturbance is constructed. Moreover, the road input from the front wheel to the rear wheel time delay is modelled with Pade approximation. These suspension characteristics and the time delay are modelled with liner model. The disturbance accommodating $H_{\infty}$ control which considers the vehicle model including the suspension characteristic is proposed. In the control, we set the lateral acceleration of the vehicle to one of controlled outputs. New semi-active suspension control method is proposed to reduce the vehicle vibration and vehicle lateral motion due to the road input. To verify the feasibility of the proposed method, several numerical simulations are carried out.

\section{Modeling}

\subsection{Modeling of the vehicle}

Figure 2 shows a full vehicle model which is equipped with semi-active suspension between each wheel and the vehicle body. The weight of the vehicle body is supported by the spring. We assume that a vehicle model is a generic sedan car as shown in Table 1 . The equations of motion which are, lateral, bounce, roll, pitch, yaw, and each unsprung motion are as follows: 


$$
\begin{aligned}
& \begin{aligned}
\left(M_{b}+\right. & \left.4 M_{t}\right) V\left(\frac{d \beta}{d t}+\gamma\right)=F_{y 1}+F_{y 2}+F_{y 3}+F_{y 4} \\
M_{b} \ddot{Z}_{c g}= & -K_{f} z_{s 1}-C_{f} \dot{z}_{s 1}+F_{1}-K_{f} z_{s 2}-C_{f} \dot{z}_{s 2}+F_{2} \\
& \quad-K_{r} z_{s 3}-C_{r} \dot{z}_{s 3}+F_{3}-K_{r} z_{s 4}-C_{4} \dot{z}_{s 4}+F_{4}
\end{aligned} \\
& I_{r} \ddot{\phi}= T_{f} / 2\left[-K_{f}\left(z_{s 1}-z_{s 2}\right)-C_{f}\left(\dot{z}_{s 1}-\dot{z}_{s 2}\right)+\left(F_{1}-F_{2}\right)\right] \\
&+T_{r} / 2\left[-K_{r}\left(z_{s 3}-z_{s 4}\right)-C_{r}\left(\dot{z}_{s 3}-\dot{z}_{s 4}\right)+\left(F_{3}-F_{4}\right)\right] \\
&+G_{m}\left(F_{y 1}+F_{y 2}\right)\left(h_{c g}-h_{r f}\right)+G_{m}\left(F_{y 3}+F_{y 4}\right)\left(h_{c g}-h_{r r}\right)+M_{b s} g H_{r} \phi \\
& I_{p} \ddot{\theta}=-L_{f}\left(-K_{f} z_{s 1}-C_{f} \dot{z}_{s 1}+F_{1}-K_{f} z_{s 2}-C_{f} \dot{z}_{s 2}+F_{2}\right) \\
&+L_{r}\left(-K_{r} z_{s 3}-C_{r} \dot{z}_{s 3}+F_{3}-K_{r} z_{s 4}-C_{4} \dot{z}_{s 4}+F_{4}\right)+M_{b} g H_{p} \theta \\
& I_{y} \frac{d \gamma}{d t}=\left(F_{y 1}+F_{y 2}\right) l_{f}-\left(F_{y 3}+F_{y 4}\right) l_{r} \\
& M_{t i} \ddot{z}_{u i}= K_{t} z_{t i}-F_{i}-K_{f} z_{s i}-C_{i}(t) \dot{z}_{s i}(i=1,2) \\
& M_{t i} \ddot{z}_{u i}= K_{t} z_{t i}-F_{i}-K_{r} z_{s i}-C_{i}(t) \dot{z}_{s i}(i=3,4)
\end{aligned}
$$

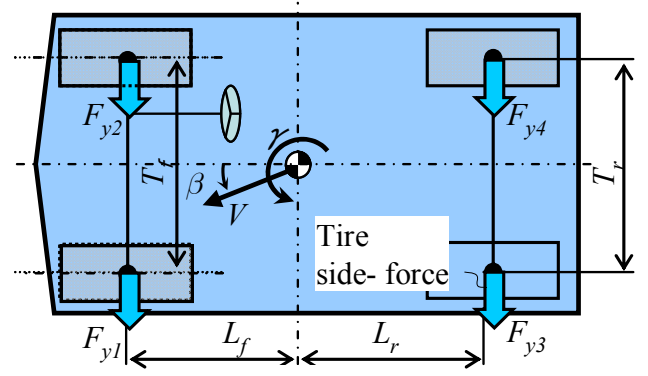

Plane view

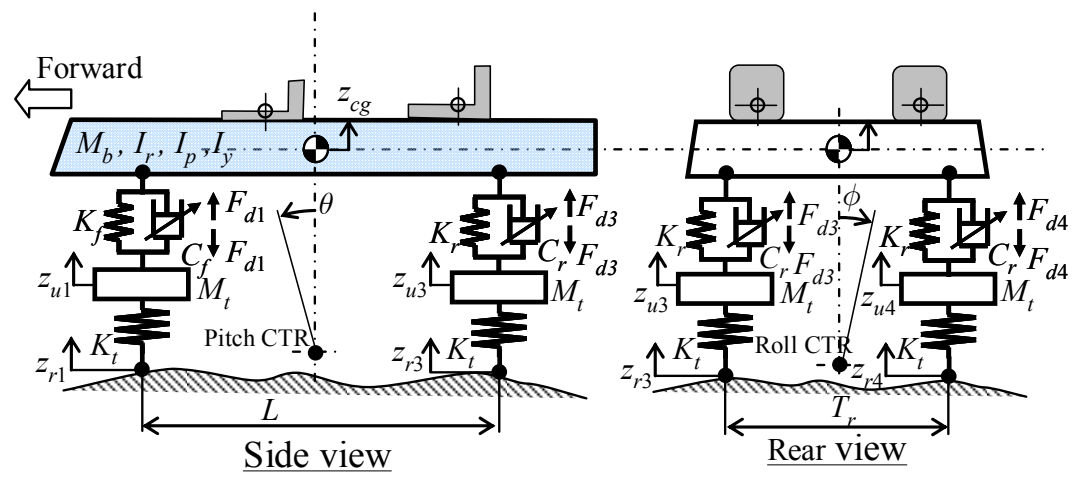

Figure 2. Vehicle model

where $H_{r}$ is the distance from a roll center to the CoG of the vehicle body, and $H_{p}$ is the distance from a pitch center to the CoG of the vehicle body. These parameters are constant. 
The spring coefficients of each wheel are different from each other, and were set to $K_{1,2}=K_{f}$, $K_{3,4}=K_{r}, F_{y i}$ means a tire side force, $z_{s i}$ means a suspension stroke of each wheel, $z_{t i}$ means deformation of the each tire.

$$
\begin{aligned}
& z_{s 1}=z_{c g}+T_{f} / 2 \phi-L_{f} \theta-z_{u 1} \\
& z_{s 2}=z_{c g}-T_{f} / 2 \phi-L_{f} \theta-z_{u 2} \\
& z_{s 3}=z_{c g}+T_{r} / 2 \phi+L_{r} \theta-z_{u 3} \\
& z_{s 4}=z_{c g}-T_{r} / 2 \phi+L_{r} \theta-z_{u 4} \\
& z_{t i}=z_{r i}-z_{u i}(i=1 \ldots 4)
\end{aligned}
$$

As shown in Fig.2, tire side force is caused by the toe change and the scuff. The toe change and the scuff are caused by the suspension stroke and the tire side force. The tire side force of each tire, $F_{y i}$, is as follows:

$$
\begin{aligned}
& F_{y 1}=K_{C f}^{\prime}\left(-\beta-\frac{L_{f}}{V} \gamma-K_{s f} z_{s 1}+\frac{2 h_{r f}}{T_{f} V} \dot{z}_{s 1}\right) \\
& F_{y 2}=K_{C f}^{\prime}\left(-\beta-\frac{L_{f}}{V} \gamma+K_{s f} z_{s 2}-\frac{2 h_{r f}}{T_{f} V} \dot{z}_{s 2}\right) \\
& F_{y 3}=K_{C r}^{\prime}\left(-\beta+\frac{L_{r}}{V} \gamma-K_{s r} z_{s 3}+\frac{2 h_{r r}}{T_{r} V} \dot{z}_{s 3}\right) \\
& F_{y 4}=K_{C r}^{\prime}\left(-\beta+\frac{L_{r}}{V} \gamma+K_{s r} z_{s 4}-\frac{2 h_{r r}}{T_{r} V} \dot{z}_{s 4}\right)
\end{aligned}
$$

where, a value in the parenthesis in Eq.(3) means the tire slip angle of each tire. $K_{s f}$ and $K_{s r}$ are the coefficient of toe angle change caused by suspension stroke. The third term in the parenthesis is the toe angle change caused by the suspension stroke of each wheel, as shown in Table 2 (A). The fourth term in the parenthesis is the tire slip angle caused by the scuff per unit time as shown in Table 2 (B). The equivalent cornering stiffness which includes the compliance steer is as follows:

$$
K_{C i}^{\prime}=\frac{K_{C i}}{1-K_{C i} K_{S F i}}(i=1, \ldots, 4)
$$

where, $K_{C i}$ is the cornering stiffness of each tire. $K_{S F i}$ is the coefficient of the toe angle change caused by the tire side force, as shown is Table 2 (C). Finally, the characteristic shown in Table 2 (D) is derived from a first order delay of the equivalent cornering stiffness (Eq. (4)).

\begin{tabular}{|l|c|c|}
\hline Input & Toutput & Scuff \\
\hline Suspension stroke & Modeling (A) & Modeling (B) \\
\hline Tire side-force & Modeling (C) & Modeling (D) \\
\hline
\end{tabular}

Table 2. Modeling of suspension characteristics 


\begin{tabular}{l|ll||l|ll}
\hline Symbol & Value & & Symbol & Value & \\
\hline$K_{s f}$ & 0.13 & $\mathrm{rad} / \mathrm{m}$ & $K_{S F f}$ & $8.0 \times 10^{-6}$ & $\mathrm{rad} / \mathrm{N}$ \\
$K_{S r}$ & 0.13 & $\mathrm{rad} / \mathrm{m}$ & $K_{S F r}$ & $1.0 \times 10^{-6}$ & $\mathrm{rad} / \mathrm{N}$ \\
$K_{C f}$ & 77000 & $\mathrm{~N} / \mathrm{rad}$ & $K_{P F f}$ & $6.7 \times 10^{-6}$ & $\mathrm{~m} / \mathrm{N}$ \\
$K_{C r}$ & 71000 & $\mathrm{~N} / \mathrm{rad}$ & $K_{P F r}$ & $6.7 \times 10^{-6}$ & $\mathrm{~m} / \mathrm{N}$ \\
\hline
\end{tabular}

Table 3. Specification of suspension characteristics

$$
\begin{aligned}
& G_{d i}(s)=\frac{1}{T_{i} s+1} \\
& T_{i}=\frac{K_{C i} K_{P F i}}{V\left(1-K_{C i} K_{S F i}\right)}(i=1, \ldots, 4)
\end{aligned}
$$

where, $K_{P F i}$ is the coefficient of the scuff caused by the tire side force. The characteristics of the tire side change is modelled from Equations (3) to (5). As shown in Table 3, each parameter is determined that stability factor was set to the usual value, $1.43 \times 10^{-3} \mathrm{~s}^{2} / \mathrm{m}^{2}$ based on the reference [18].

\subsection{Vehicle response caused by antiphase road disturbance}

The state equation of the vehicle model which reflects change the tire side force is defined as Eq. (6). This model is an LTI model when the vehicle velocity is fixed.

$$
\begin{aligned}
& \dot{x}=A_{P} x(t)+B_{P 1} w(t)+B_{u} u(t) \\
& x(t)=\left[\begin{array}{llllllllllllllllll}
z_{u 1} & z_{u 2} & z_{u 3} & z_{u 4} & z_{c g} & \phi \theta & \dot{z}_{u 1} & \dot{z}_{u 2} & \dot{z}_{u 3} & \dot{z}_{u 4} & \dot{z}_{c g} \dot{\phi} \dot{\theta} \beta & \gamma & F_{y 1} & F_{y 2} & F_{y 3} & F_{y 4}
\end{array}\right]^{T} \in \mathbb{R}^{20} \\
& w(t)=\left[\begin{array}{llll}
z_{r 1} & z_{r 2} & z_{r 3} & z_{r 4}
\end{array}\right]^{T} \\
& u(t)=\left[\begin{array}{llll}
F_{1} & F_{2} & F_{3} & F_{4}
\end{array}\right]^{T}
\end{aligned}
$$

We confirmed that the vehicle responsed to an antiphase road disturbance. In this research, the phases of road input of left-right are zero and $\pi$. Zero means a coordinate phase, and $\pi$ means the antiphase. In the antiphase road, the road displacement at the vehicle velocity, $V$, is as follows.

$$
z_{r 2}=-z_{r 1}, z_{r 3}=e^{-\frac{L}{V} s} z_{r 1}, z_{r 4}=-e^{-\frac{L}{V} s} z_{r 1}
$$

The transfer function of the vehicle responce caused by the antiphase road disuturbance at $33.3 \mathrm{~m} / \mathrm{s}(120 \mathrm{~km} / \mathrm{h})$ is shwon in Fig. 3. Here, Figure 3 (a) is the date of previous study. Figure $3(\mathrm{~b})$ is the data of our study. In these figures, specification of the vehicle model of each study is different. However, from the result showing the same tendency for vehicle responses, we found that the our model is appropriate. 


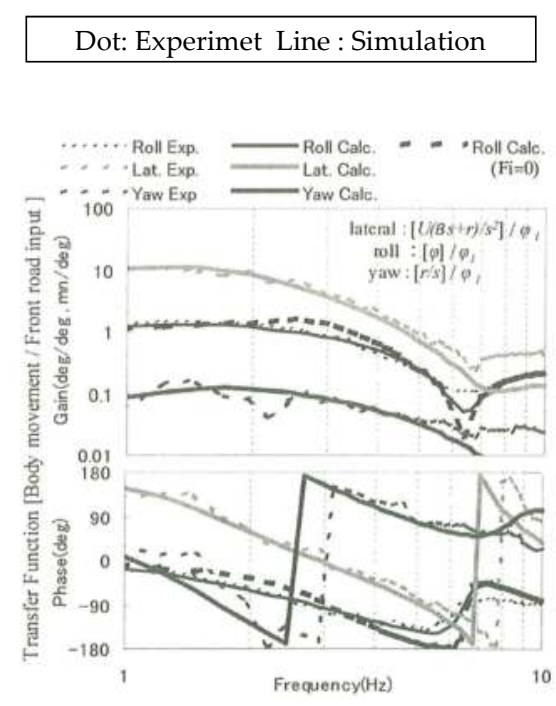

(a) Previous study (Koumura, 2008)

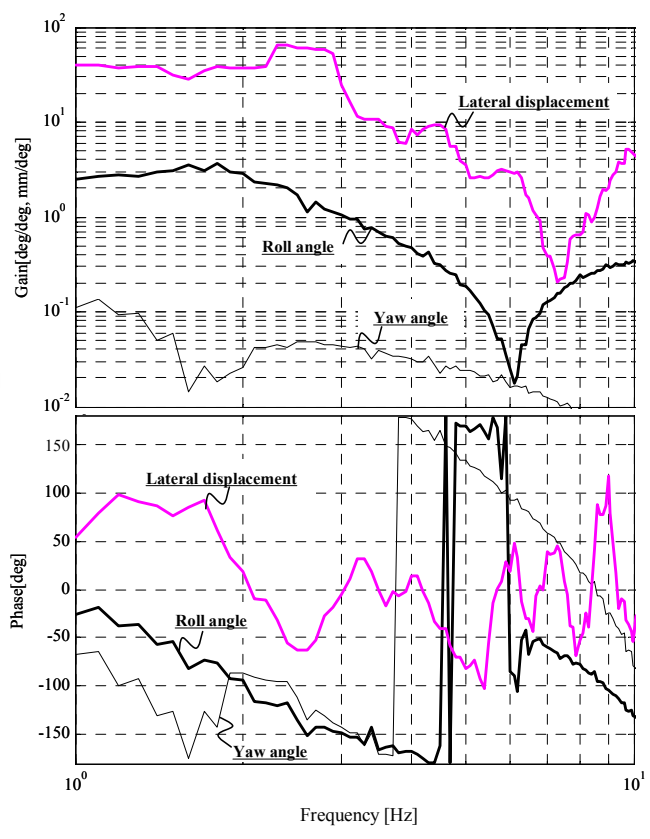

(b) Our study (Simulation)

Figure 3. Vehicle responce coused by antiphase road disuturbance

\subsection{Design of damper coefficient}

In general, the performance of the controller is affected by the damping coefficients of the suspension. In this section, we design the damping coefficient for the evaluation values which are the vertical acceleration at the coordinate phase road and the lateral acceleration at the antiphase road. In the next section, we design the control system which uses the damping coefficients designed in this section. The road condition is shown in Figs. 4 and 5. The road displacement is assumed such that the Power Spectral Density (PSD) characteristic of the road surface is $C$ class defined by ISO [19]. The lateral accelerations are shown in Fig. 8 and the lateral acceleration of vehicle body are derived from a geometric relation as follows.

$$
\ddot{y}_{c g}=\ddot{y}_{R C}-H_{r} \ddot{\phi}
$$




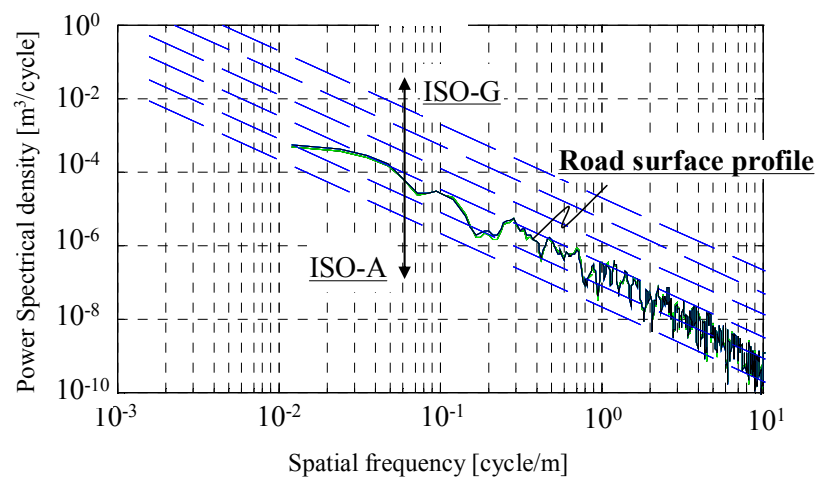

Figure 4. Power spectral density of road surface profile[19]

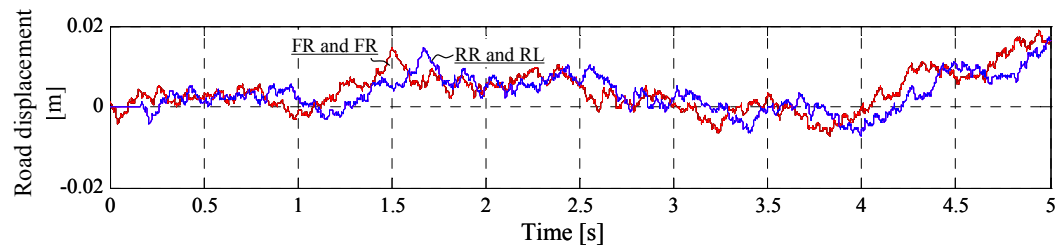

(a) Coordinate phase

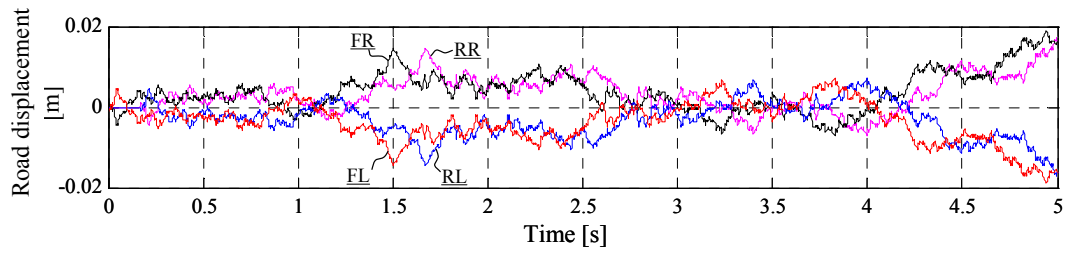

(b) Antipahse

Figure 5. Road displacement

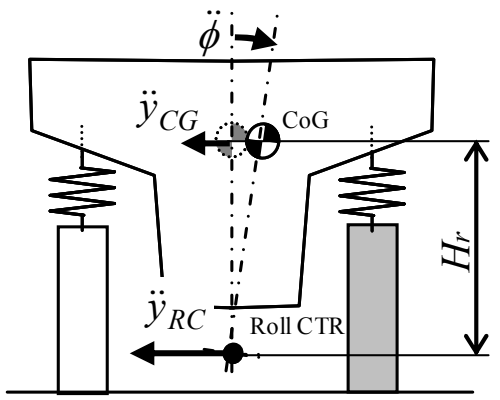

Figure 6. Lateral acceleration (Rear view) 


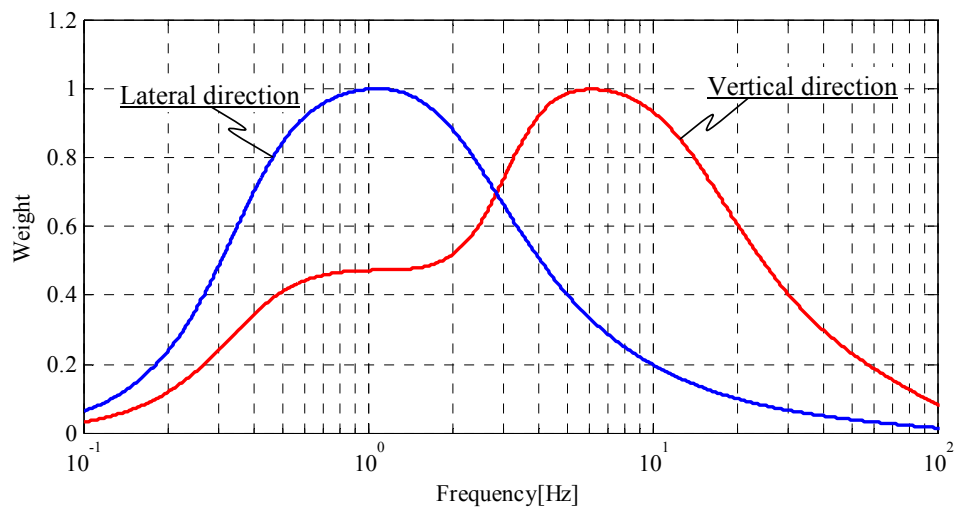

Figure 7. Sensitivity curves of lateral and vertical acceleration [20]

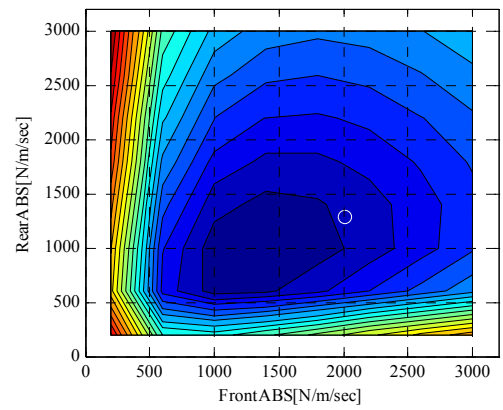

(a) Vertical acceleration (Coordinate phase road)
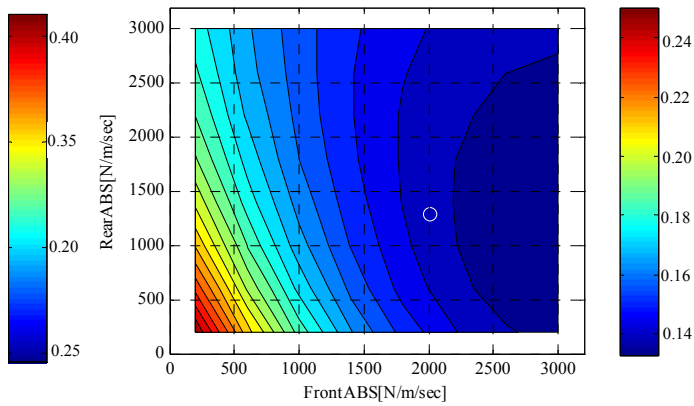

(b) Lateral acceleration (Antiphase road)

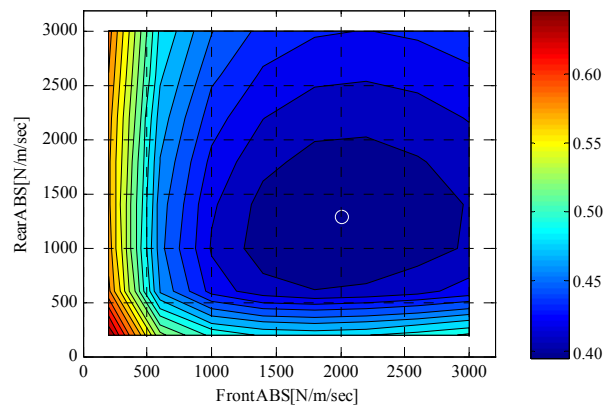

(c) Sum of Vertical and lateral acceleration $((a)+(b))$

Figure 8. Contour diagram of RMS value of accelerations (unit : $\mathrm{m} / \mathrm{s}^{2}, \mathrm{O}:$ minimum point of (c)) 
The sensitivity curves of the lateral and the vertical acceleration are defined by ISO [20]. We designed the damping coefficient for the suspension to minimize the Root Mean Square (RMS) which considers the sensitivity curves. A frequency response of the filter [21] which modeled sensitivity curve with the transfer function is shown in Fig. 7. We calculated the RMS values using the time history of the vertical and lateral accelerations which pass this filter. The simulation results when both front and rear damping coefficients are changed are shown in Fig. 8, which is a contour diagram of the RMS values. There are minimum point in Fig. 8 (a), (b) and (c). The evaluation value is the sum of vertical and lateral acceleration of RMS shown in Fig. 8. (c). From the simulation results, the damping coefficients of the suspension are 2000 and $1300 \mathrm{~N} / \mathrm{m} / \mathrm{s}$.

\section{Controller design}

We used the controller designed based on the linear $H_{\infty}$ control theory to a semi-active suspension. The control system of the semi-active suspension is shown in Fig. 9. An actuator force command $F_{l i}$ is calculated with the linear $H_{\infty}$ controller. The damping force command $F_{d i}$ is translated with a liner-bilinear converter.

\subsection{Approximation of time delay of road disturbances}

When the front and rear tire passes the same path, road disturbance affects the rear tire has the delay to the front tire. As shown in Fig. 10, the road input from the front wheel to the rear wheel is the delayed. The delay is modeled with a third-ordered Pade approximation. As shown in Fig. 10 (b), we consider the effect of vehicle velocity in the control system design by using a linear model. To check whether the Pade approximation is correct, we carried out the numerical simulations. The response of the vehicle model which includes the Pade approximation when the vehicle runs on the antiphase road disturbance is shown in Fig. 11. The vehicle velocity is $16.7 \mathrm{~m} / \mathrm{s}(60 \mathrm{~km} / \mathrm{h})$. In the lower frequency of the resonance frequency of the tire, we found that the result of the simulation model which uses the time delay and Pade approximation are almost the same.

\subsection{Disturbance-accommodating control}

We found that feedforward control of disturbance information in the finite frequency range and feedback control improve performance [22]. The power spectral density of the actual velocity of disturbances had flat characteristics in a low frequency, and decreased according to frequency at a region of high frequency. We assumed that it regarded as the colored noise formed by shaping filter which has a transfer function with low-pass characteristics. This filter of the each wheel is based on the road condition which defined by ISO ${ }^{[19]}$. The filter is as follows:

$$
\begin{gathered}
Q_{w}\left\{\begin{array}{l}
\dot{x}_{w i}(t)=A_{w i} x_{w i}(t)+B_{w i} w_{g i}(t) \\
w_{w i}(t)=c_{w i} x_{w i}(t) \quad(i=1, \ldots, 4)
\end{array}\right. \\
\frac{w_{w i}(s)}{w_{g i}(s)}=\frac{\varpi_{d}{ }^{2}}{s^{2}+2 \xi_{d} \varpi_{d} s+\varpi_{d}{ }^{2}} \quad(i=1, \ldots, 4)
\end{gathered}
$$


where, $w_{g i}$ is road input of the each wheel, $w_{i}$ is road input of the vehicle model of the general model as shown in Fig. 7. It was referred to as $\varpi_{d}=50 \times 2 \pi$ and $\xi_{d}=0.706$.

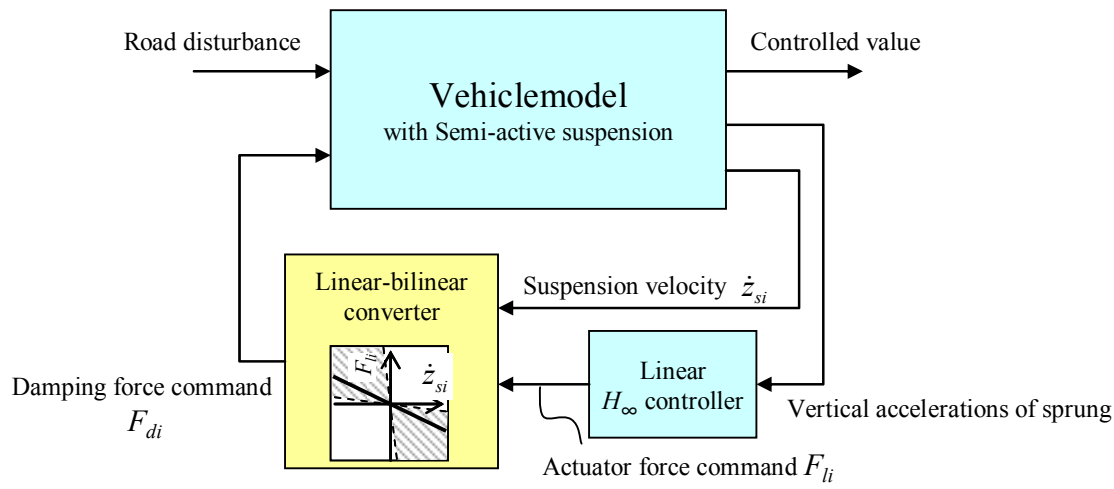

Figure 9. Control system of semi-active suspension

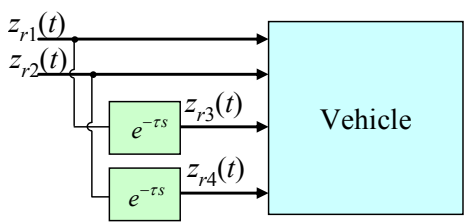

(a) Real world

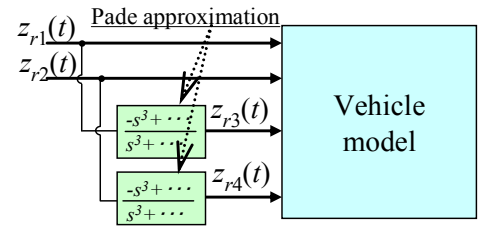

(b) Modeling
Road disturbance

$z_{r 1}:$ Front-Left

$z_{r 2}:$ Front-Right

$z_{r 3}:$ Rear-Left

$z_{r 4}:$ Rear-Right

Figure 10. Approximation of time delay of road disturbances from front to rear wheels. 


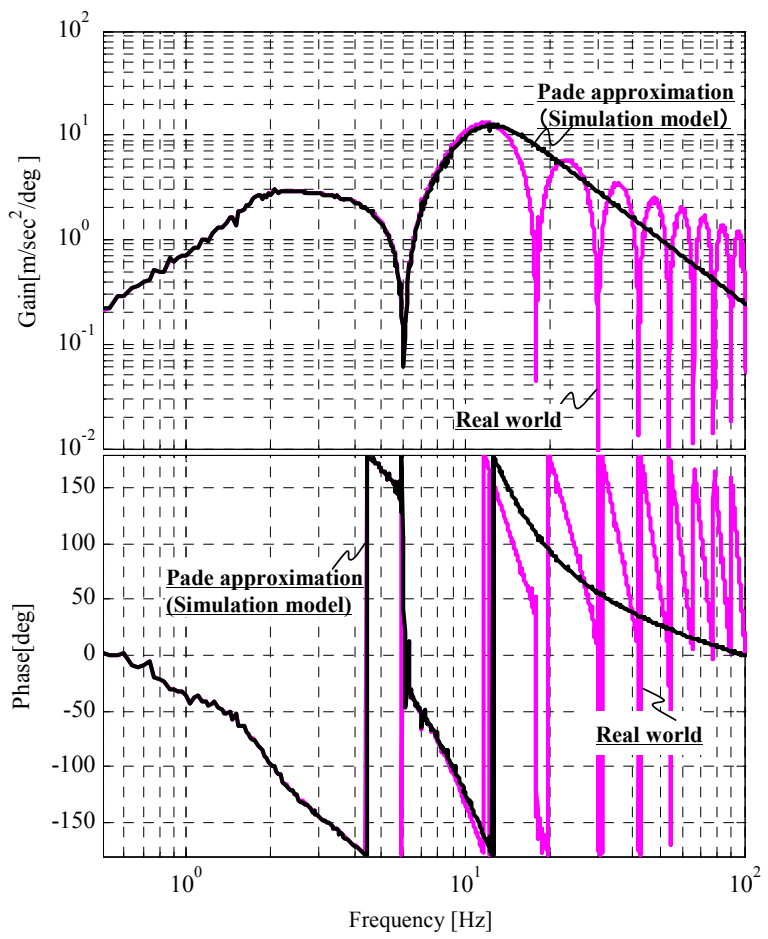

Figure 11. Vehicle response of vehicle model which includes the Pade approximation caused by antiphase road disturbance

\subsection{Disturbance-accommodating $H_{\infty}$ control}

The feedforward control of disturbances resulted in worse accuracy outside the assumed frequency [22]. Furthermore, because each resonance frequency of the vehicles and tire differs, the control system design considering each resonance frequency is needed. Therefore, the control system was designed by using the $H_{\infty}$ method in the control theory.

We integrated each state variable of the road disturbance model and frequency weights for controlled values. The frequency weights are as follows:

$$
\begin{array}{r}
Q_{z c}\left\{\begin{array}{c}
\dot{x}_{z c}(t)=A_{z c} x_{z c}(t)+B_{z c} x(t) \\
z_{z c}(t)=c_{z c} x_{z c}(t)+D_{z c} x(t)
\end{array}\right. \\
Q_{z i}\left\{\begin{array}{c}
\dot{x}_{z i}(t)=A_{z i} x_{z i}(t)+B_{z i} u(t) \\
z_{z i}(t)=c_{z i} x_{z i}(t)+D_{z i} u(t)
\end{array}\right.
\end{array}
$$

where, $z z c$ is controlled value of the vehicle motion, $z z i$ is controlled value of the control input. Figure 7 shows a block diagram of the generalized plant to design the controller, and the state-space form of the generalized plant is as follows: 


$$
\left\{\begin{array}{l}
\dot{x}_{g}(t)=A_{g} x_{g}(t)+B_{g 1} w_{g}(t)+B_{g 2} u(t) \\
z_{g}(t)=C_{g 1} x_{g}(t)+D_{g 11} w_{g}(t)+D_{g 12} u(t) \\
y_{g}(t)=C_{g 2} x_{g}(t)+D_{g 22} u(t)
\end{array}\right.
$$

$H_{\infty}$ norm of the transfer function $G_{z_{g} w_{g}}$ from disturbance $w_{g}(t)$ to controlled value $z(t)$ is expressed by the following equation.

$$
\operatorname{miu}_{u}\left\|G_{Z_{g} W_{g}}\right\|_{\infty}=\sup _{w} \frac{\left\|z_{g}\right\|_{2}}{\left\|w_{g}\right\|_{2}}=: \gamma^{*}
$$

where, $\gamma^{*}$ is a minimum of $H_{\infty}$ norm of the generalized plant realized with $H_{\infty}$ controller. The controller is the following equation [23].

$$
\left\{\begin{array}{l}
\dot{x}_{k}(t)=A_{k} x_{k}(t)+B_{k} y_{g}(t) \\
u(t)=C_{k} x_{k}(t)
\end{array}\right.
$$

In this reserch, we assumed that the vehicle speed is constant. The measured outputs, $y(t)$, are four vertical accelerations of the wheel position of the vehicle body. The controlled values, $z(t)$, are vertical acceleration, lateral acceleration, vertical velocity of the vhicle body, tire deformation, and actuating force. Frequency weight $W_{i}$, shown in Fig. 13, was determined by trial and error.

A bandpass filter, $W_{1}$, that had a peak frequency equal to the resonance frequency of the passenger's head was used based on sensitivity curves [20], such as that being standardized by ISO and shown in Fig. 4 . The low pass filter, $W_{2}$, was used based on sensitivity curves of lateral direction. In order to prevent the increase of response in each resonance, a low pass filter $W_{3}$ and a bandpass filter $W_{4}$ are used. Moreover, to prevent steady control input, a high pass filter, $W_{5}$, was used.

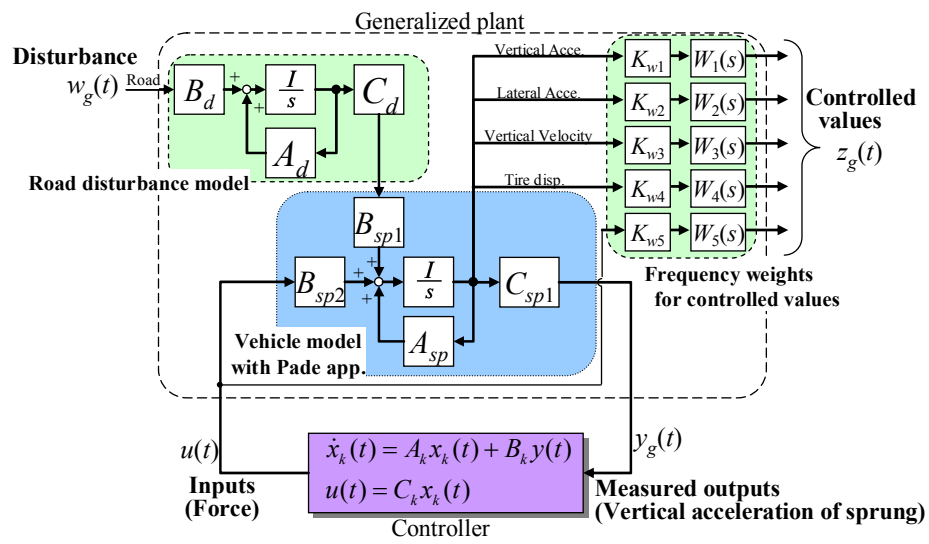

Figure 12. Generalized plant 


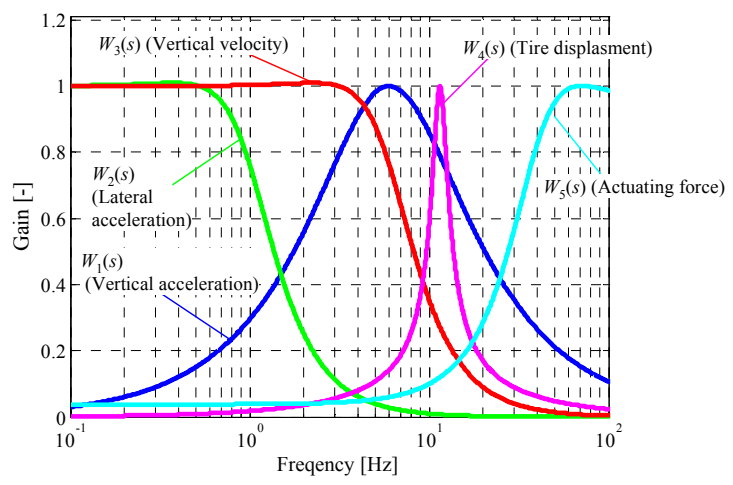

Figure 13. Frequency weight

\subsection{Comparison of the response of the frequency weight $K_{w 2}$}

To check the effect of the suspension model which includes the tire side force caused by the road disturbance, we compared two control systems, one which considers the tire side force and the control system, and one which does not consider one. The design of two general control methods changed the controlled value of the lateral acceleration of the vehicle body. Frequency weights, $W_{1}, W_{2}, W_{3}, W_{4}, K_{w 1}=500, K_{w 3}=500, K_{w 4}=2000$, and $K_{w 5}=20$, are the same value in the proposed method and general methods. We combined the control system and vehicle model which includes the tire side force shown in Chapter 2. We used MATLAB (The Math Work Inc.) to calculate the Runge-Kutta method for the differential equations. The computational time step is $1 \mathrm{~ms}$. Vehicle velocity is $16.7 \mathrm{~m} / \mathrm{s}(60 \mathrm{~km} / \mathrm{h})$. The road surface conditions are shown in Fig. 5(b). We calculated the RMS values from the time history of lateral acceleration which passes the filter shown in Fig.7.

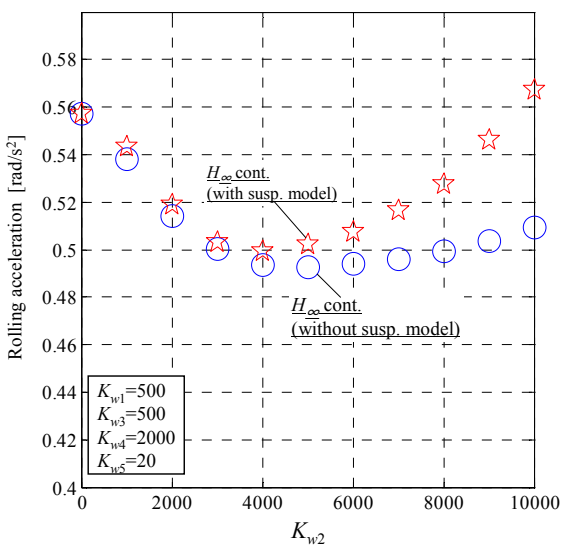

(a) Rolling acceleration

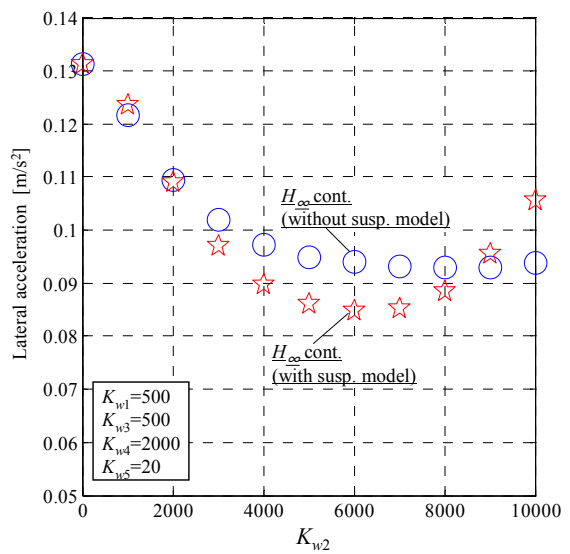

(b)Lateral acceleration

Figure 14. RMS value changed by evaluation function of accelerations (Antiphase road) 
The RMS value changed by the frequency weight, $K_{w 2}$ is shown in Fig. 14. For a frequency weight, $K_{w 2}$, is 1 to 4000 , when $K_{w 2}$ increases, the RMS value of rolling and lateral accelerations decreased. Furthermore, when $K_{w 2}$ increases, RMS of lateral acceleration decreased. From the result of Fig. 14.(b), it was confirmed that the proposed method can reduce the lateral acceleration due to the road disturbance in comparison with the general method. We compare the control performance of two controllers which are designed using the frequency weight shown in Fig. 14.(b). In two controllers, $K_{w 2}$ is set the smallest RMS value in 14.(b).

\section{Simulation}

\subsection{Simulation condition}

To clarify the effect of the suspension model which includes the tire side force, we compare the two control systems. The two control systems are designed in Cheater 3. As for the control system which inflects the tire side force ( $H_{\infty}$ cont. (with susp. model)), the frequency weight of lateral acceleration, $K_{w 2}$, is 4000 . The control system which does not consider the tire side force $\left(H_{\infty}\right.$ cont. (without susp. model)), the frequency weight of lateral acceleration, $K_{w 2}$, is 6000 .

In the simulation, we combine the control system and the vehicle model which includes the tire side force shown in Chapter 2. The vehicle velocity is $16.7 \mathrm{~m} / \mathrm{s}(60 \mathrm{~km} / \mathrm{h})$. Moreover, we assume that the range of the damping coefficient of the semi-active suspension is $100-10000 \mathrm{~N} / \mathrm{m} / \mathrm{s}$ in Fig. 15. The semi-active damper has the first order delay. The cut off frequency is $10 \mathrm{~Hz}$. We used MATLAB (The Math Work Inc.) to calculate the Runge-Kutta method for the differential equations. There were two road conditions. One is the coordinate phase road in Fig. 5 (a), and the other is the antiphase road in Fig. 5 (b). To demonstrate the control effect, we show the responses which does not control he semi-active damper (Non control).

\subsection{Simulation results}

In check whether the proposed method reduced vertical and lateral motion, we did the numerical simulations. The time history of the vertical acceleration caused by the coordinate phase and the lateral acceleration caused by the antiphase road is shown in Fig. 14. The Lissajous figure for the suspension velocity and the damping force of the front suspension are shown in Fig. 15. The PSD of the vertical acceleration and the lateral acceleration is shown in Fig. 16.

In the coordinate phase road, there are few difference in the time history and the Lissajous figure. As for the PSD, two control systems can reduce the vibration better than the non control one near the resonance frequencies of the vertical direction of the vehicle body and vertical direction of the human head. On the other hand, in the antiphase road, there are differences in the time history and the Lissajous figure. The PSD of lateral acceleration, two 
control systems can reduce the vibration near the frequency range with a high level of lateral acceleration sensitivity. Additionally, the control system which includes suspension model of the tire side force change caused by road disturbance can reduce the vibration better than the control system which does not include the tire side force change in the same frequency range. The simulation results confirmed that using the proposed control system reduces the vertical and the lateral motion of the vehicle caused by the disturbance in the road.

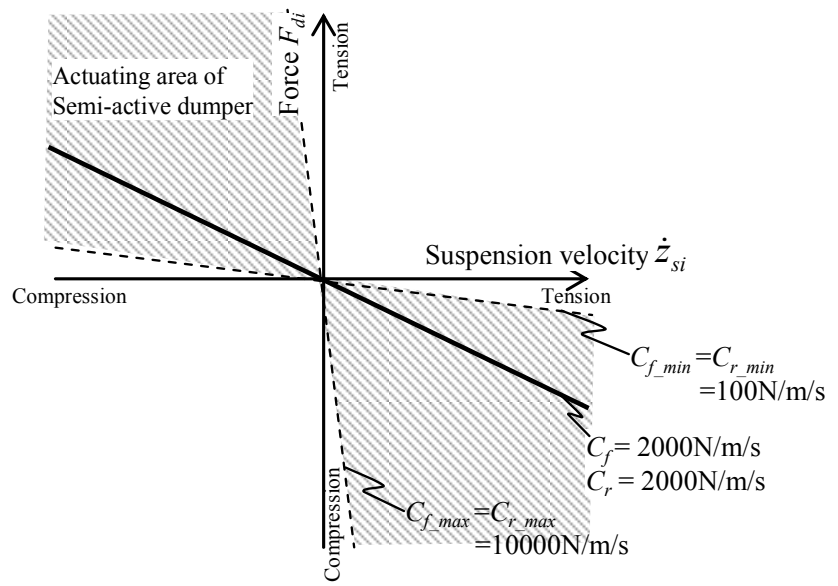

Figure 15. Semi-active dumper model

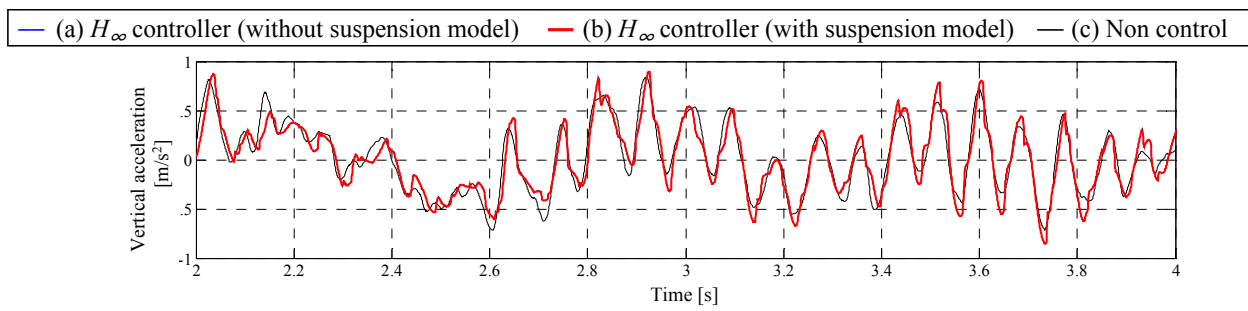

(a) Vertical acceleration (Coordinate phase road)

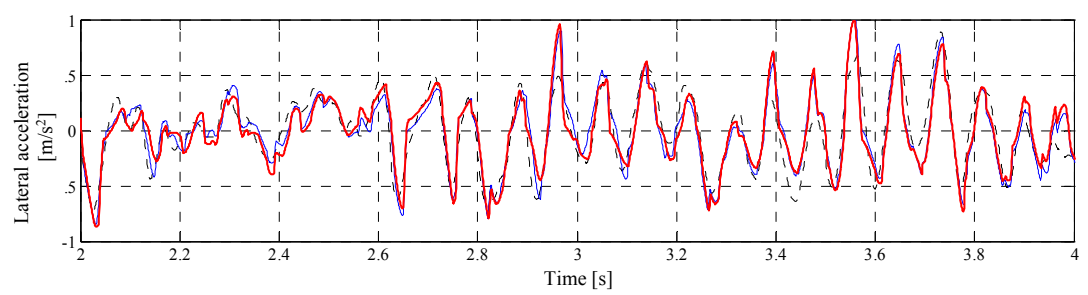

(b) Latera acceleration (Antiphase road)

Figure 16. Time history 

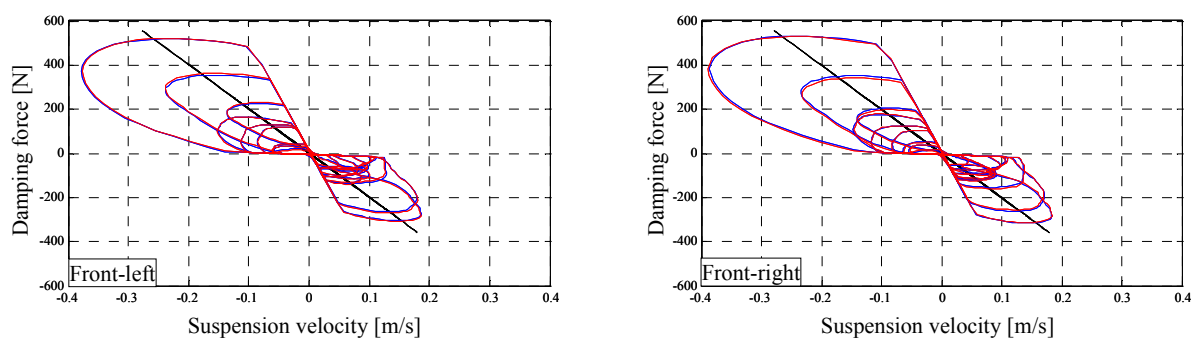

(a) Coordinate phase road
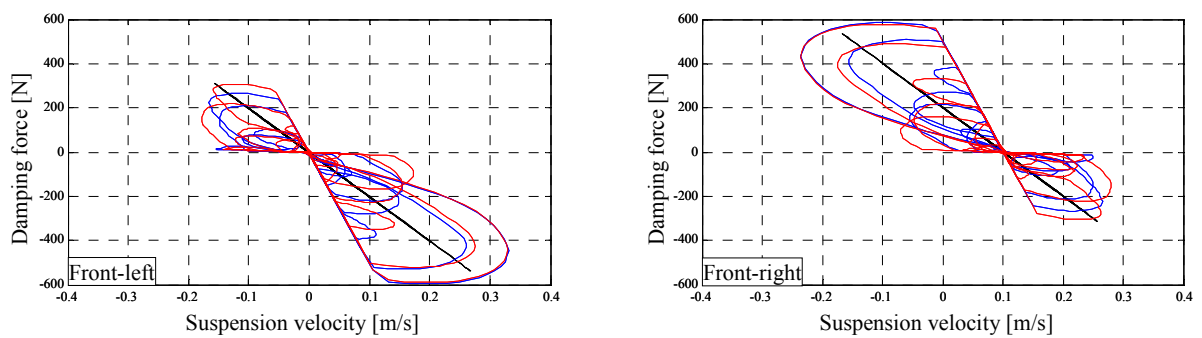

(b) Antiphase road

Figure 17. Lissajous figure (Suspension velocity and damping force)

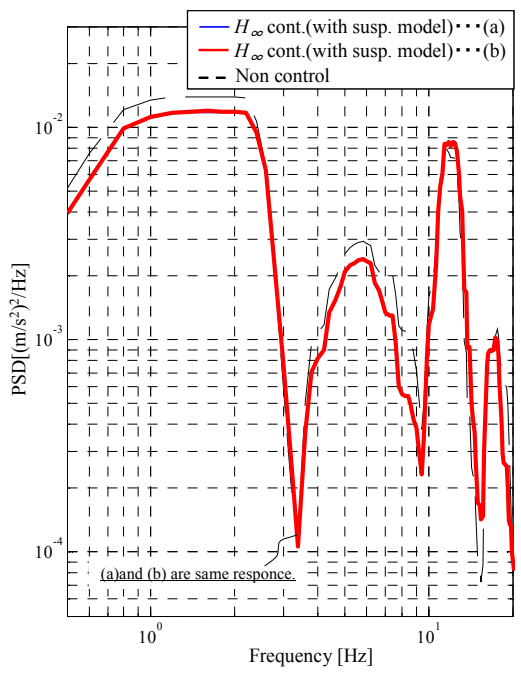

(a) Vertical acceleration (Coordinate phase)

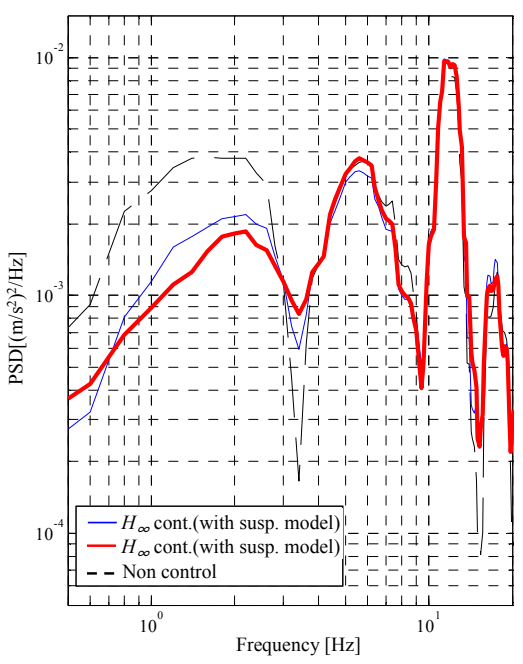

(b) Latera acceleration (Antiphase road)

Figure 18. PSD values 


\section{Conclusion}

This research proposed disturbance accommodating $H_{\infty}$ control which considers the vehicle model in order to reduce the vehicle vibration and vehicle lateral motion due to the road input. We formulate the vehicle model including the suspension characteristic that is the toe change and the scuff caused by suspension stroke and tire side force. In order to verify the feasibility of the proposed method, the numerical simulations were carried out. From the result, it was confirmed that the proposed control system is effective for reducing not only the vertical vibration but also the lateral vehicle motion due to the road disturbance in comparison with the control method without considering the suspension characteristic.

\section{Author details}

Takama Suzuki and Masaki Takahashi

Keio University, Japan

\section{References}

[1] Tanaka T, Harada M, Takizawa S, Tatemoto M, Active Controlling System of Suspension, J Japan Society of Automotive Engineering, 1998, 42(1): 92-101, (in Japanese).

[2] Kawarasaki Y, Fukunaga Y, Hasegaw H, Okuyama Y, Kurozu K, Iijima T, Development of a Hydraulic Active Suspension by Nissan, Proc Japan Society of Automotive Engineering Annual Congress, 1989, 892: 193-196, (in Japanese).

[3] Yonekawa T, Ohnuma T, Mori Y, Gotoh T, Buma S, Effect of Active Controlled Suspension System on Vehicle Dynamics, Trans Japan Society of Automotive Engineering, 1991, 22(3): 63-68, (in Japanese).

[4] Hanamura Y, Mori R, Araki Y, Harada H, Influence of Attitude Control by Active Controlled Suspension on Stability of Vehicle, Trans Japan Society of Mechanical Engineers, Series C, 1998, 64(617): 163-168, (in Japanese).

[5] Hanamura Y, Nakajo K, Araki Y, Oya M, Harada H, Control of Vehicle Maneuverability and Stability of Means of Attitude Control with Vertical Load Control, Trans Japan Society of Mechanical Engineers, Series C, 1998, 64(624): 242-247, (in Japanese).

[6] Hanamura Y, Fujita K, Araki Y, Oya M, Harada, H, Control of Vehicle Maneuverability of 4 Wheeled Vehicle by Active Suspension Control with Additional Vertical Load Control, Trans Japan Society of Mechanical Engineers, Series C, 1999, 65(629): 236-243 (in Japanese).

[7] Hamahira M, Hanamura Y, Araki Y, Oya M, Active Vehicle Suspension Control with Vertical Load Control by $H_{\infty}$ Controller, Proc Dynamics and Design Conference 1999, M108: 41-46 (in Japanese).

[8] Ikuo K, Eiich Y, Shunichi D, An Analysis of Pitch and Bounce Mouton, Requiring High Performance of Ride Comfort, Vehicle System Dynamics, 2004, 41: S83-92. 
[9] Koumura S, Analysis of Roll Lateral Vehicle Behavior by Road Input, Proc Japan Society of Automotive Engineering, Seminar of Vehicle dynamics, 2008, 08(46): 31-48, (in Japanese).

[10] Koumura S, Ohkita T, Analysis of Roll Lateral Vehicle Behavior by Road Input, Trans Japan Society of Automotive Engineering, 2008, 39(4): 23-29, (in Japanese).

[11] Koumura S, Ohkita T, Ride Comfort Evaluation through Analysis of Roll and Lateral Vehicle Behaviors Due to Rod Input, J Society of Automotive Engineering, Passenger cars - Mechanical system,2008, 2008-01-0581: 472-479.

[12] Antonio M, Nagai M, Optimal Preview Control of Rear Suspension Using Nonlinear Networks, Proc Int Symp Advanced Vehicle Control, 1992, 020: 117-122.

[13] Kimura T, Akatsu Y, Tabata H, Fumuyama K, Application of Preview Control to an Active Suspension System for Vehicle Vibration Control, Trans Japan Society of Automotive Engineering, 1994, 25(3): 93-97, (in Japanese).

[14] Araki Y, Harada H, Oya M, Preview Control of Active Suspension Using Disturbance Information of Front Wheel, Trans Japan Society of Mechanical Engineers, Series C, 1994, 60(578): 172-177 (in Japanese).

[15] Aida K, Naganawa A, Suda S, Shimomura H, Mizuguchi Y, Fundamental Study on $\mathrm{H}_{\infty}$ Preview Control in Active Suspensions for Railway Vehicles, Trans Japan Society of Mechanical Engineers, Series C, 1998, 64(621): 58-64, (in Japanese).

[16] Yu F, Zhang JW, Crolla DD, A study of a Kalman filter vehicle suspension system using correlation of front and rear wheel road input, Trans I MechE, Series D, 2000, 214: 493502.

[17] Oraby WAH, Aly MA, Ei-Demerdash SM, Selim AM, Influence of Active Suspension Preview Control on the Vehicle Lateral Dynamics, Trans Society of Automotive Engineering[CD-ROM], 2007, No.2007-01-2347.

[18] The Japan society of Automotive engineering, Automotive technology series, Technology for improvement of vehicle dynamics, Asakura-Shoten, 1998, 43-44, (in Japanese).

[19] ISO-8608:1995, Mechanical vibration -Road surface profiles- Reporting of measured data, International Organization for Standardization, 1995.

[20] ISO-2631-1:1997, Mechanical vibration and shock - Evaluation of human exposure to whole-body vibration-, International Organization for Standardization, 1997.

[21] Rimell AN and Mansfield NJ, Design of Digital Filters for Frequency Weightings Required for Risk Assessments of Workers Exposed to Vibration, Proceedings of the Industrial Health 2007, 2007, 45: 512-519.

[22] Okamoto B, Yoshida K, Bilinear Disturbance-Accommodating Optimal Control of SemiActive Suspension for Automobiles, Trans Japan Society of Mechanical Engineers, Series C, 2000, 66(650): 3297-3304 (in Japanese).

[23] Glover K, Doyle JC, State-space Formula for All Stabilizing Controllers that Satisfy an $H_{\infty}$-norm Bound and Relations to Risk Sensitivity, J Systems \& Control letters, 1988, 11: $167-172$. 